\title{
Investigation of congenital tremor associated with Classical swine fever virus genotype 2.2 in an organized pig farm in north-eastern India
}

\author{
Nagendra Nath Barman ${ }^{1} \cdot$ Elina Khatoon ${ }^{1,2} \cdot$ Mousumi Bora $^{1,3} \cdot$ Lalit Deori $^{1} \cdot$ \\ Sophia M. Gogoi ${ }^{1} \cdot$ Dhireswar Kalita $^{1}$
}

Received: 22 December 2020/Accepted: 2 March 2021/Published online: 17 March 2021

(C) Indian Virological Society 2021

\begin{abstract}
The present study describes an outbreak of Classical swine fever (CSF) in an organized pig farm followed by an episode of CSF virus (CSFV) associated congenital tremors in piglets. The outbreak was recorded in a newly procured herd of Hampshire pigs housed adjacent to the existing pigs of the farm. The recorded CSF outbreak caused a mortality of $100 \%$ in the newly procured and $54.28 \%$ in the existing herd. As the disease subsides, the clinically recovered boars were served naturally with Tamworth gilts. Though, the sows farrowed on usual gestation period, litters born to each sow showed congenital tremors and eventually died within $24 \mathrm{~h}$ of birth. Necropsy analysis of affected piglets was indicative of CSFV infection and was further confirmed using RT-PCR signifying a transplacental infection. The CSFV strains from the initial outbreak and post outbreak episode of congenital tremors were successfully isolated in PK-15 cells and detected in indirect FAT and RT-PCR. Phylogenetic analysis based on E2 gene and $5^{\prime}$ NTR of CSFV grouped the isolates within the genotype 2.2 and revealed close resemblance with previously reported Indian isolates of CSFV genotype 2.2 origin. To the best of our knowledge, this is the first report of CSFV induced congenital form reported from India under natural conditions.
\end{abstract}

Nagendra Nath Barman

nnbarman@gmail.com

1 Department of Microbiology, College of Veterinary Science, Assam Agricultural University, Khanapara Campus, Guwahati, Assam 781022, India

2 Department of Biosciences and Bioengineering, Indian Institute of Technology, Guwahati, Assam 781039, India

3 Faculty of Veterinary and Animal Sciences, Banaras Hindu University, Mirzapur, Uttar Pradesh 231001, India
Keywords Classical swine fever virus - Transplacental infection · Congenital tremor · Piglets · Phylogenetic characterization - Genotype 2.2

Classical swine fever (CSF) or Hog Cholera is a highly contagious viral disease of domestic and wild pigs with severe economic consequences [30].The disease is caused by Classical swine fever virus (CSFV), a positive-sense, enveloped virus belonging to the genus Pestivirus of the family Flaviviridae [19].CSFV genome comprises of a single open reading frame $(12.3 \mathrm{~kb})$, flanked by two nontranslated regions ( $5^{\prime}$ and $3^{\prime}$-NTRs) which encodes a polyprotein composed of about 3898 amino acids, which is processed by viral and cellular enzymes into four structural (C, Erns, E1 and E2) and eight non-structural proteins ( ${ }^{\text {pro }}, \mathrm{P} 7, \mathrm{NS} 2, \mathrm{NS3}, \mathrm{NS} 4 \mathrm{~A}, \mathrm{NS} 4 \mathrm{~B}, \mathrm{NS} 5 \mathrm{~A}$, and NS5B) [16]. Although CSF has been successfully eradicated from several countries (Canada, USA, Australia and the European Union), it remains endemic in certain areas of Asia, Europe, Central and South America and parts of Africa representing a constant threat to the pig industry [4, 33]. CSFV has three major genotypes (1,2 and 3). Genotype 1 comprises of seven sub-genotypes $(1.1,1.2,1.3,1.4,1.5$, 1.6 and 1.7$)$, while three to four sub-genotypes $(2.1,2.2$, $2.3 ; 3.1,3.2,3.3$ and 3.4) have been reported for genotype 2 and 3 based on phylogenetic analysis of $5^{\prime}$ NTR, E2 glycoprotein gene and $3^{\prime}$ end of the NS5B polymerase gene [16]. Indian CSFV isolates have so far been grouped into three sub-genotypes, 1.1 [37], 2.1 [35] and 2.2 [32, 40].

CSFV exhibits a variety of disease modes in pigs with infections that may be acute, chronic or persistent [4, 29]. The severity of the disease depends on the virulence of CSFV, age and status of host animals [20]. In general, infection with moderate to highly virulent strains result in 
acute form of CSF which is characterized by high fever $\left(>40{ }^{\circ} \mathrm{C}\right)$, conjunctivitis, respiratory signs, constipation followed by diarrhoea, skin haemorrhages, lethargy and neurological symptoms such as convulsions and staggering gait following death within 1-2 weeks [3, 4, 27]. Chronic presentation of the disease is characterized by clinical signs such as remittent fever, depression, wasting and diffuse dermatitis [4]. Persistent infection of CSF usually requires infection of sows during pregnancy and manifests congenital and post-natal infections in piglets [13, 31].

Congenital and post-natal infections in piglets have been reported with different forms including per-acute, acute and chronic [17]. Depending upon the time of gestation and viral virulence, trans-placental infection of foetuses may result in abortions, stillbirths, mummification, malformations, congenital tremors after birth or birth of apparently healthy piglets, but persistently infected with CSFV [9, 30]. Persistently infected piglets usually show poor growth and wasting and eventually succumb to death [43]. The congenital-persistent form of CSF is known as 'pregnant carrier sow syndrome' [9]. Persistence of CSFV has also been reported in experimental post-natal infection of piglets [30] and weaned pigs [9, 44]. Pigs with persistent infection of CSFV tend to shed the virus for months, either continuously or intermittently representing a constant source of infection within the pig population [7]. In the present study, we investigated an outbreak of CSF in an organized pig farm of north-eastern India with a subsequent episode of congenital tremors in new born piglets. The study revealed interesting data pertaining to the prevalence of CSFV associated congenital persistent form in natural conditions.

An outbreak of CSF was recorded in an organized pig farm located in Khanapara region of Assam, a state in north-eastern India. The farm housed a group of newly procured crossbred Hampshire pigs $(n=30)$ along with the existing animals of the farm that includes Hampshire boars $(\mathrm{n}=35)$ and Tamworth gilts $(\mathrm{n}=25)$. The outbreak initially occurred in the group of newly procured Hampshire pigs comprising of both boars and gilts of 6-8 months of age with no history of prophylactic vaccination against CSF. The existing pigs of the farm, however, had a history of primary vaccination with lapinised CSF vaccine (Weybridge strain, UK) at 3 months of age. The affected pigs showed CSFV specific clinical symptoms such as high fever $\left(>40{ }^{\circ} \mathrm{C}\right)$, hyperemia of skin following respiratory distress and recumbency for 10-15 days till death. None of the pigs from the newly introduced stock could survive the infection. Simultaneously, similar clinical symptoms were observed in the group of existing Hampshire boars housed adjacent to the affected sty where 19 out of 35 pigs died of the CSFV infection. The sty that housed the Tamworth gilts was seemed to be unaffected and the gilts were found to be apparently healthy. Necropsy of the dead pigs were performed and tissue samples for detection of CSFV were collected from both the affected stys. Detection of CSFV antigen was done by direct fluorescent antibody test (FAT) for in-situ demonstration of antigen on tissue cryosections as described earlier by Barman et al. [2].

Following the initial outbreak, the Hampshire boars that have recovered the CSFV infection were served with three Tamworth gilts through natural service within a month of recovery. Though the sows farrowed on usual time of gestation, piglets in each litter presented moderate to severe tremors instantly after birth along with atleast one or two stillborn piglets. The tremors in piglets were characterized by systemic muscle spasms resulting in severe tremors in the flank and legs. The hind legs were observed with a splay of one or both the legs making them unable to stand up and suckle on a teat (Fig. 1). The severity of tremors was found to be relatively constant throughout the litters over the observation period of $24 \mathrm{~h}$ (hrs) until death. Tissue samples (tonsils, kidney, spleen and lymph nodes) collected during piglet necropsies were processed for histopathological evaluation. Further, detection and isolation of CSFV was done considering the previous outbreak of CSF and its possibility in vertical transmission.

Histopathological evaluation was conducted on $4 \mu \mathrm{m}$ thin sections of paraffin-embedded formalin-fixed tissue samples stained with haematoxylin/eosin (HE). Detection of CFSV genome was done using nested Reverse-transcription polymerase chain reaction (RT-PCR) to detect the E2 gene and $5^{\prime}$ NTR of CSFV using published primer sets [18, 23] (Table 1). Viral RNA was extracted using the QIAamp RNA Kit (QIAgen, Hilden, Germany) according to the manufacturer's instructions. The cDNA was synthesized using $6 \mu \mathrm{g}$ of viral RNA using SuperScript ${ }^{\mathrm{TM}}$ III First-Strand Synthesis System (Invitrogen, USA). PCR was carried out in $50 \mu \mathrm{l}$ of total reaction volume containing $5 \mu \mathrm{l}$ of $10 \times$ PCR buffer, $3 \mu \mathrm{l}$ of $25 \mathrm{mM} \mathrm{MgCl}_{2}, 1 \mu \mathrm{l}$ of each forward and reverse primers $(20 \mathrm{pM}), 1 \mu \mathrm{l}$ of $10 \mathrm{mM}$ dNTPs, $0.5 \mu \mathrm{l}$ of Taq DNA polymerase (Promega, Madison, USA), $33.5 \mu \mathrm{l}$ of nuclease free water (NFW) and $5 \mu \mathrm{l}$ of cDNA template. The PCR components were mixed properly and amplified as per the conditions mentioned in Table 2. For nested amplification of E2 gene and 5'NTR, the procedure was essentially the same except that the template cDNA was replaced by $5 \mu$ of primary PCR amplicons. The amplified products were resolved in $1 \%$ agarose gel (Amresco, Cleveland, USA) containing ethidium bromide $(0.5 \mu \mathrm{g} / \mathrm{ml})$ and visualized under UV transilluminator (Kodak, Biostep, Germany) for documentation of results.

Representative CSFV positive clinical samples from the initial outbreak and post outbreak congenital tremor were processed separately for isolation in pig kidney (PK-15) cells (ATCC, USA) grown using EMEM (Sigma, USA) 
Fig. 1 Piglets exhibiting congenital tremors with hind leg splays and dog-sit posture

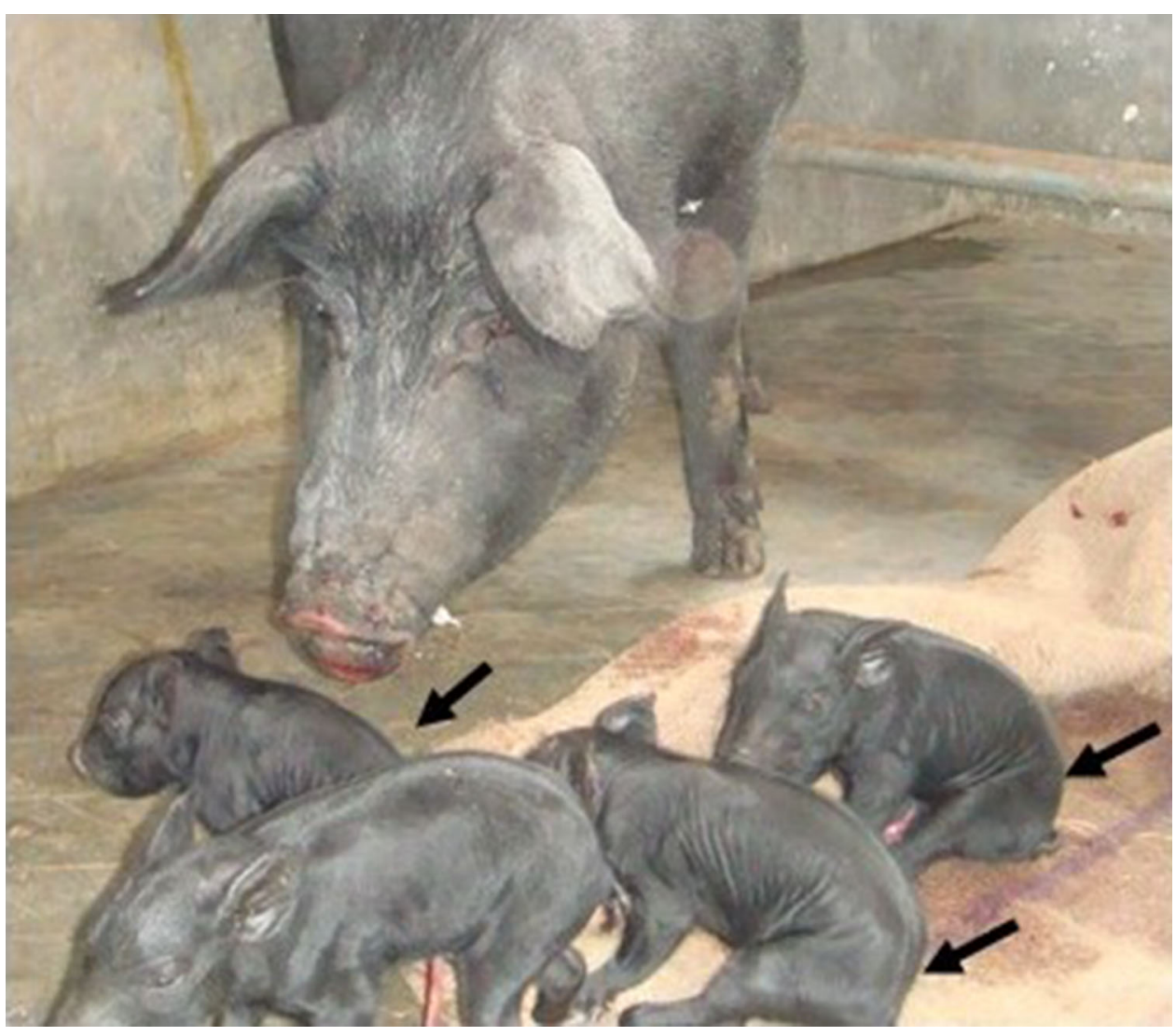

Table 1 Description of primers used in the present study

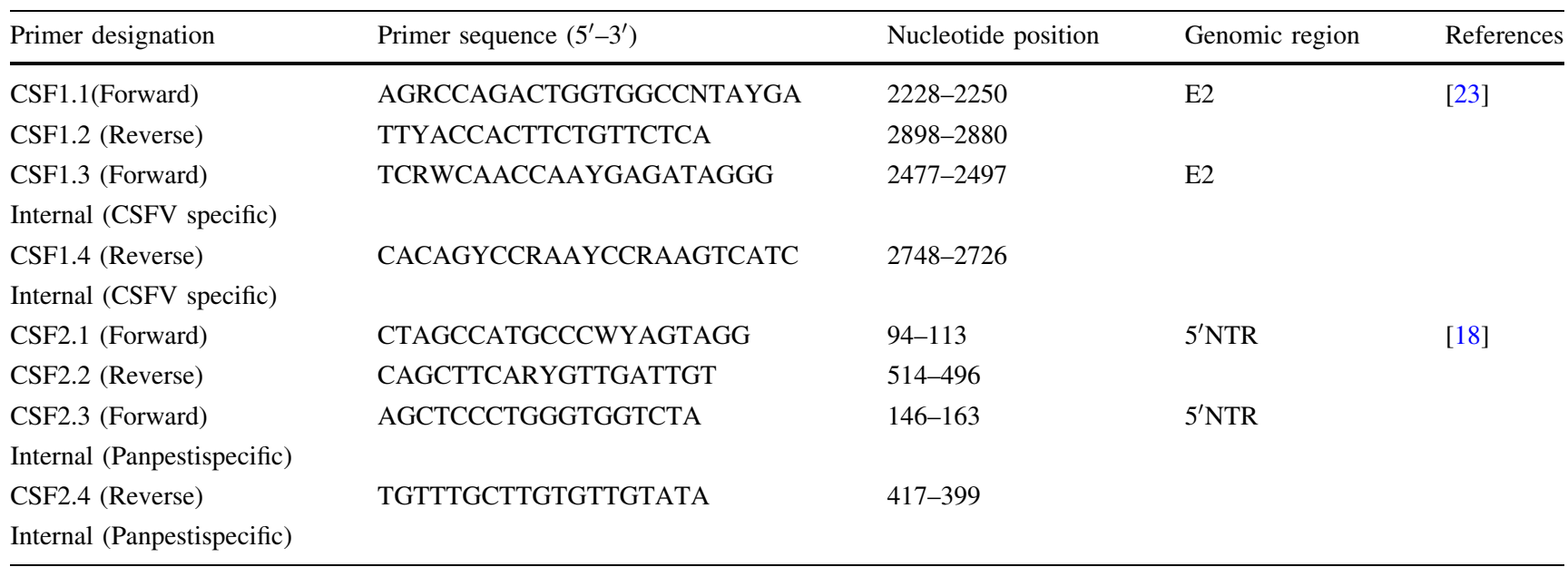

supplemented with $10 \%$ pestivirus-free foetal bovine serum (Invitrogen, USA). A $20 \%$ tissue suspension in EMEM treated with glutamine and antibiotic solution (Himedia, Pennsylvania, USA) was used to infect the cell monolayer grown in $25 \mathrm{~cm}^{2}$ cell culture flask through adsorption for one hr at $37{ }^{\circ} \mathrm{C}$ with $5 \% \mathrm{CO}_{2}$. The cells infected with CSFV positive samples were harvested 4-days post infection (dpi) and stored at $-80{ }^{\circ} \mathrm{C}$ deep freezer. The harvested cells $(5 \mathrm{ml})$ were subjected to two cycles of freeze-thaw and the cell debris was removed by centrifugation at $10,000 \mathrm{rpm}$ for $10 \mathrm{~min}$ at $4{ }^{\circ} \mathrm{C}$. One $\mathrm{ml}$ of the supernatant was used as inoculum for subsequent three serial passages. The virus harvest at third passage was confirmed by RTPCR and indirect FAT using WH303 monoclonal antibody (AHVLA, UK).

The RT-PCR amplicons of CSFV isolates were purified using PureLink ${ }^{\mathrm{TM}}$ Quick gel extraction kit (ThermoFisher) and sequenced using commercial sequencer (ABI Prism, 
Table 2 Thermal cycling conditions for amplifying enveloped protein (E2) and $5^{\prime} \mathrm{NTR}$ region of CSFV

\begin{tabular}{lllll}
\hline Stage & Steps & Temperature $\times$ Time for amplifying E2 gene & Temperature $\times$ Time for amplifying $5^{\prime}$ NTR & No of Cycles \\
\hline 1 & Initial denaturation & $95{ }^{\circ} \mathrm{C} \times 2 \mathrm{~min}$ & $95{ }^{\circ} \mathrm{C} \times 2 \mathrm{~min}$ & 1 \\
2 & Denaturation & $95{ }^{\circ} \mathrm{C} \times 30 \mathrm{~s}$ & $95{ }^{\circ} \mathrm{C} \times 30 \mathrm{~s}$ & 34 \\
3 & Annealing & $56{ }^{\circ} \mathrm{C} \times 45 \mathrm{~s}$ & $50{ }^{\circ} \mathrm{C} \times 45 \mathrm{~s}$ & $72{ }^{\circ} \mathrm{C} \times 1 \mathrm{~min}$ \\
4 & Extension & $72{ }^{\circ} \mathrm{C} \times 1 \mathrm{~min}$ & $72{ }^{\circ} \mathrm{C} \times 1 \mathrm{~min}$ & 1 \\
5 & Final extension & $72{ }^{\circ} \mathrm{C} \times 1 \mathrm{~min}$ & & 1 \\
\hline
\end{tabular}

For nested amplification using internal set of primers, the annealing temperatures were kept $58{ }^{\circ} \mathrm{C}$ for E2 and $56{ }^{\circ} \mathrm{C}$ for $5^{\prime} \mathrm{NTR}$ respectively

3100, IL, USA). The generated sequences with GenBank accession numbers KJ645982, KJ645981, KJ885559 and KT852941 were analyzed by comparing the sequences of different genotypes of CSFV available in GenBank database using CLUSTAL W program of MEGA 6 software. The evolutionary history was inferred using the NeighborJoining algorithm and the evolutionary distances were computed using the maximum composite likelihood method [42]. The pairwise similarity among the nucleotide sequences was calculated using MegAlign program from Lasergene Molecular Biology software (DNASTAR Inc., Madison, USA).

The outbreak of CSF in newly procured crossbred Hampshire pigs caused a mortality of $100 \%$. Eventually, the existing Hampshire boars that showed clinical symptoms similar to the pigs in the newly procured group recorded a mortality rate of $54.28 \%$. The presence of CSFV in infected tissue sections of tonsil, spleen and kidneys was demonstrated by direct FAT showing bright green cytoplasmic fluorescence (Fig. 2), thus confirming the outbreak to be CSF.

Following the initial outbreak, the piglets that exhibited congenital tremors showed some pathological lesions which can be related to gross pathological lesions observed in CSFV infections. Piglet necropsies showed swollen haemorrhagic lymph nodes and tonsils. Focal pin-point haemorrhages in the subcapsular region and diffuse haemorrhages in subcortical areas of the kidneys were observed. Splenic infarction was observed in the form of congested small raised haemorrhagic areas (Fig. 3). On histopathological evaluation, microscopic changes suggestive of CSFV infection were observed. The most prominent lesion in kidney was interstitial nephritis and focal areas of acute glomerular nephritis characterized by swelling of the glomerular tuft, expanded up to the bowman's space with cellular infiltration (Fig. 4a). In spleen, focal to diffuse haemorrhages were observed in the red pulp with a depletion of lymphocytes in the splenic corpuscles (Fig. 4b). In the lymph nodes, depletion of lymphocytes in the lymphoid follicle and necrosis with cellular debris and haemorrhages were observed (Fig. 4c). Representative tissue samples tested using RT-PCR to amplify E2 and $5^{\prime}$ NTR of CSFV provided an expected amplification of $271 \mathrm{bp}$ (Fig. 5a), thus confirming the etiological agent of post outbreak episodes of congenital tremors in piglets as CSFV.

Positive samples from the initial outbreak of CSF and post outbreak episode of congenital tremor in piglets were isolated in PK-15 cells after three blind serial passages. CSFV isolation (CSF/As/430 and CSF/As/437) in PK-15 cells was confirmed by RT-PCR (results not shown) and indirect FAT (Fig. 5b). Phylogenetic analysis of the CSFV isolates based on the E2 and $5^{\prime} \mathrm{NTR}$ sequences were grouped under subgenotype 2.2 of genotype 2 along with previously published Indian CSFV isolates. The E2 gene based phylogenetic analysis grouped the two CSFV isolates (GenBank accession numbers KJ885559 and KT852941) within the CSFV genotype 2.2 detected earlier from Mizoram, Arunachal Pradesh and other northern Indian states that have confirmed the emergence of genotype 2.2 in published reports [35] (Fig. 6). Based on E2 gene sequences, the isolates of the present study shared a percent identity of $100 \%$ within themselves, $98.4 \%$ with a previously reported CSFV isolate from Hisar (EU567075), while 95-97.6\% with the other isolates of genotype 2.2. The $5^{\prime}$ NTR sequence based phylogenetic tree (Fig. 7) grouped the two CSFV isolates (KJ645981 and KJ645982) within the clade of genotype 2.2 and showed a $100 \%$ of nucleotide identity within themselves as well as with the previously reported CSFV isolate from Hisar (EU567079). The CSFV isolates exhibited 98.6-99.5\% nucleotide identities among the other isolates of subgroup 2.2 as per pairwise nucleotide identities based on $5^{\prime}$ NTR sequences.

The present study describes an outbreak of CSF in domestic pigs with a follow up episode of congenital tremor in an organized farm located in Assam, a north-eastern state of India. Pig farming is a usual practice among the tribal community and small land holders of Assam and its neighboring states as a primary source of livelihood, food security and employment. The pig industry of this region is 

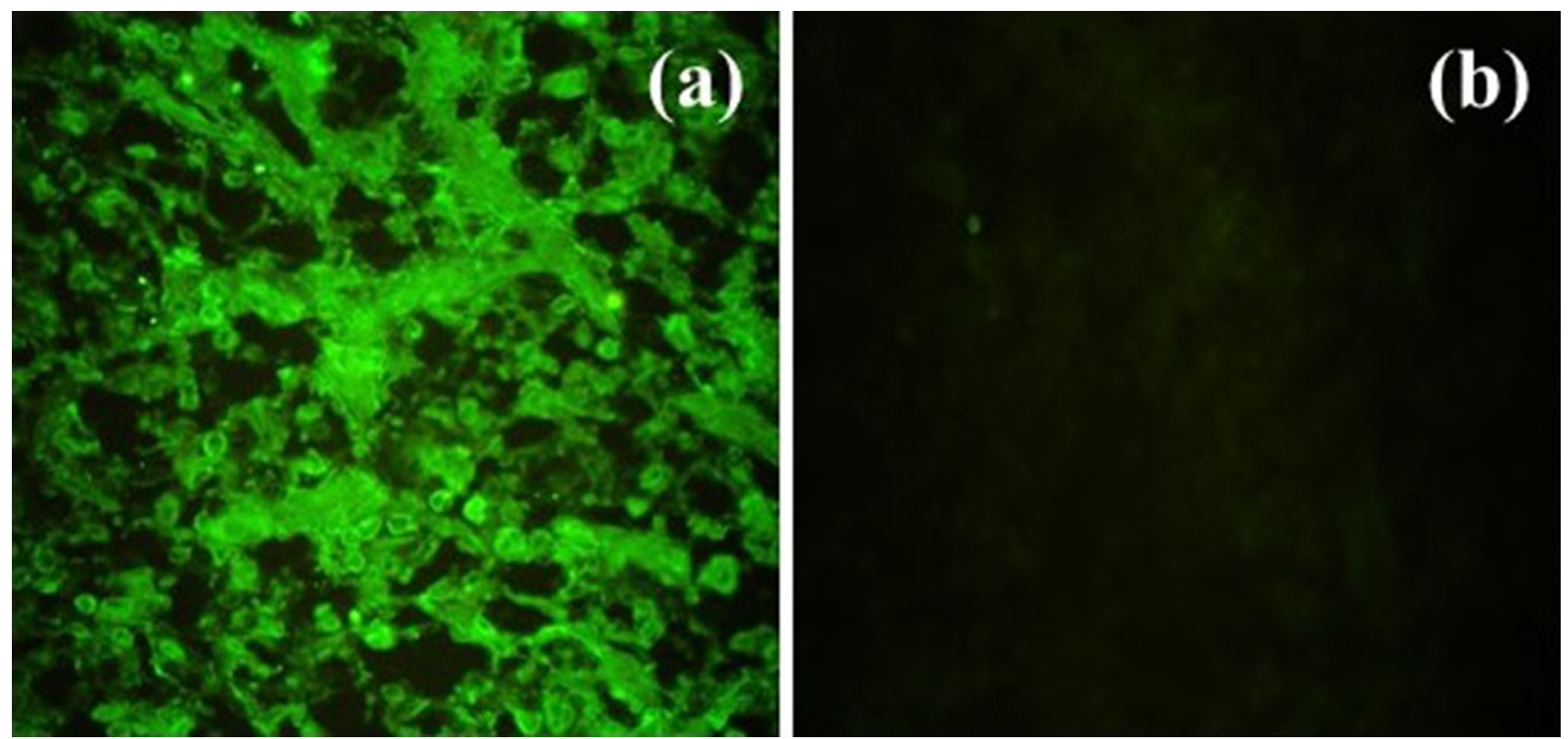

Fig. 2 a A cryosection of kidney of CSFV affected Hampshire boar showing bright green cytoplasmic fluorescence. b No fluorescence was observed in cryosection of kidney of a healthy pig $(400 \times)$
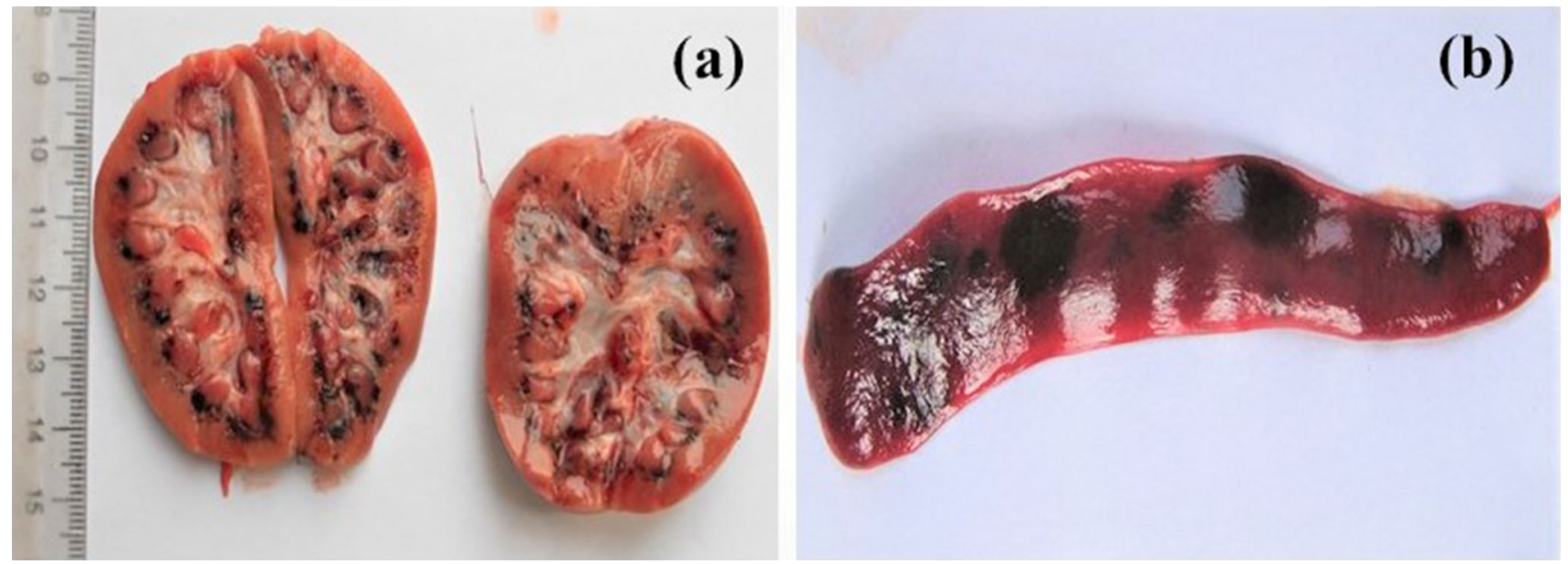

Fig. 3 Gross pathological finding in a 24 h-old piglet died after exhibiting post-parturition tremors a Petechial haemorrhages in renal cortex b Splenic infarction

not well developed in terms of effective disease management, modern abattoirs and waste disposal systems. Recent outbreaks of emerging and transboundary pig viral diseases like Porcine reproductive and respiratory syndrome [36] and African swine fever [6] have significantly increased the risk of infections in the domestic as well as wild pig population. Among the various other infections of pigs reported from this region, CSF remains to be the most predominant infection associated with mortalities and reproductive failures in domestic pigs [22, 25, 38]. Besides, unavailability of CSF vaccines in sufficient doses to control CSF is another major drawback because of which the disease is frequently reported in endemic foci throughout the country [26]. Currently, in India, both lapinized and cell-culture adapted lapinized CSF vaccines (Weybridge strain, UK), based on genotype-1.1 are being used to control the disease [24].

In this study, the CSF outbreak in the organized pig farm might have occurred through introduction of the newly procured Hampshire pigs $(n=30)$, housed within the same farm premise where existing groups of Hampshire boars $(\mathrm{n}=35)$ and Tamworth gilts $(\mathrm{n}=25)$ were maintained. Clinical signs suggestive of CSF such as high fever $\left(>40{ }^{\circ} \mathrm{C}\right)$, lethargy, anorexia, skin hemorrhages and respiratory distress were first recorded in the newly procured Hampshire pigs. The infection from the affected sty spread 

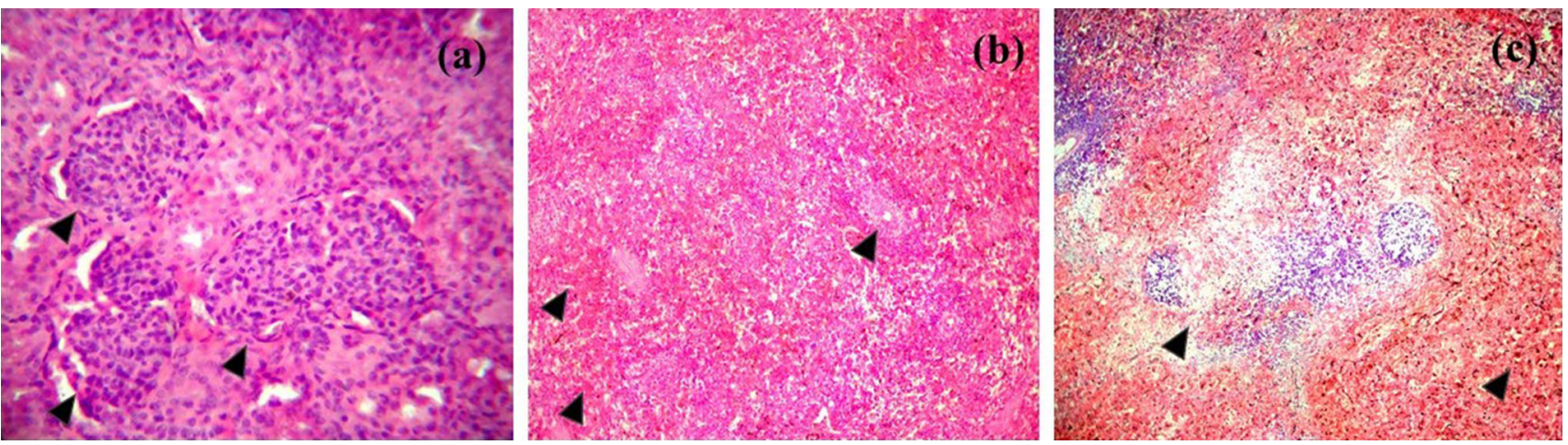

Fig. 4 Histopathological changes seen in piglets associated with congenital tremors, HE staining. a Kidney; interstitial nephritis and focal areas of acute glomerular nephritis characterized by swelling of the glomerular tuft, b spleen; focal to diffuse haemorrhages in the red pulp with a depletion of the lymphocyte in the splenic corpuscles, c lymph node; depletion of lymphocytes in the lymphoid follicle and necrosis with cellular debris and haemorrhages
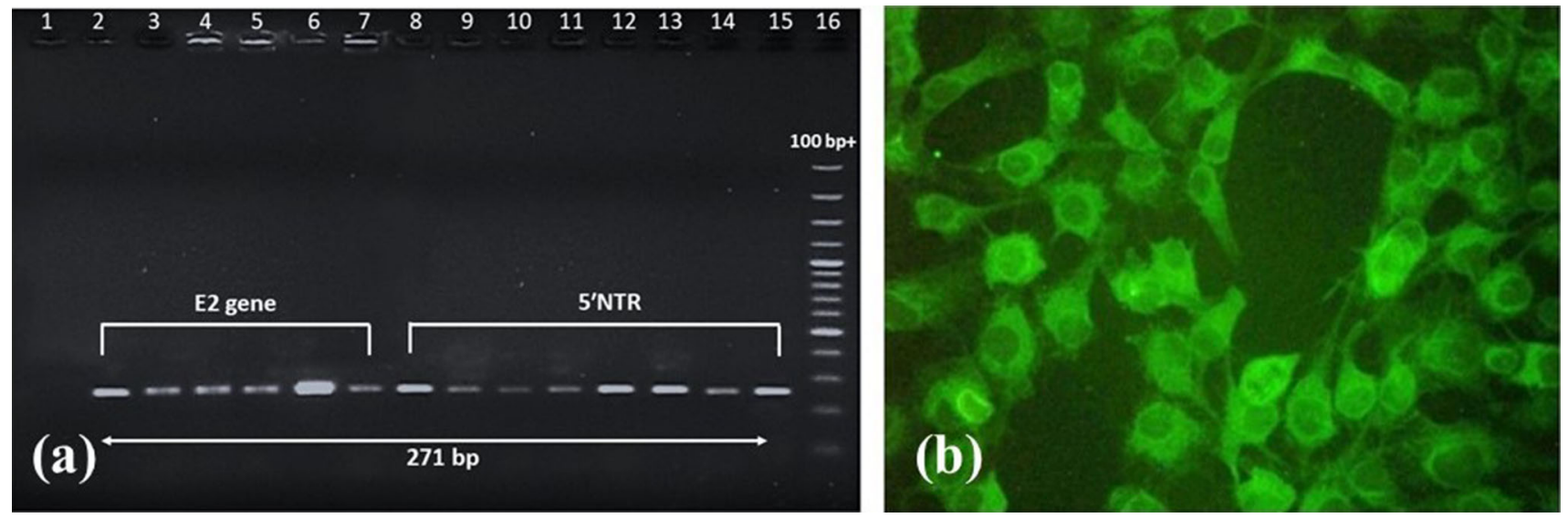

Fig. 5 a Agarose gel electrophoresis showing amplification of E2 gene and $5^{\prime}$ NTR (271 bp) regions of CSFV in tissue specimens of piglets died exhibiting congenital tremors; Lane 1: non template control; Lane 2: E2 gene positive control; Lane 3-7: amplification of
E2 gene in tissue samples; Lane 8: $5^{\prime}$ NTR positive control; Lane 9-15: amplification of $5^{\prime}$ NTR in tissue samples; Lane 16: 100 bp plus DNA ladder (GeneRuler). b Immunofluorescence staining of isolation of CSFV in PK-15 cells at $72 \mathrm{~h}$ post infection $(\times 200)$ at passage 3 to the adjacent sty and infected the existing Hampshire boars, which, however had a history of prophylactic vaccination with CSF lapinized vaccine comprising the Weybridge strain, UK at 3 months of age. In both the newly procured and existing group of pigs that have suffered a simultaneous CSFV infection, the clinical symptoms were indicative of acute form of CSF that might have caused by a moderate to highly virulent strain of CSFV considering the duration of disease progression (10-14 days) and high mortality rate. The outbreak killed $100 \%$ of newly procured Hampshire pigs and nearly $54.28 \%$ of existing Hampshire boars. The CSF outbreak in newly procured Hampshire pigs can be related to an already incubating CSFV infection since the clinical symptoms were apparent within a week of procurement. Simultaneous infection of CSFV to existing Hampshire boars can be related to low or sub-optimum CSFV neutralizing antibody titres and lack of effective biosecurity in containment of CSFV in the affected sty where the newly procured unvaccinated Hampshire pigs were maintained. The possible explanation to low or suboptimum CSFV neutralizing antibody titres can be related to an unexpected vaccine failure after primary vaccination and could be due to (i) interference of maternal antibody titres (ii) requirement of a second booster dose, (iii) instability of the vaccine under environmental conditions and/or (iv) inability of the vaccine to provide herd immunity. Similar reports of low CSFV serum neutralizing titres have been reported with the Chinese strain (C-strain) of CSF vaccine after primary vaccination of pigs and have recommended the use of second boosting for an effective immune response [13]. Inhibition of successful active immunization of $\mathrm{C}$-strain vaccine by maternal antibodies derived from vaccinated sows has also been reported in previous studies [34, 41]. Routine assessment of maternal antibodies titres and estimation of serum neutralizing titres against CSFV after primary vaccination is not a usual 


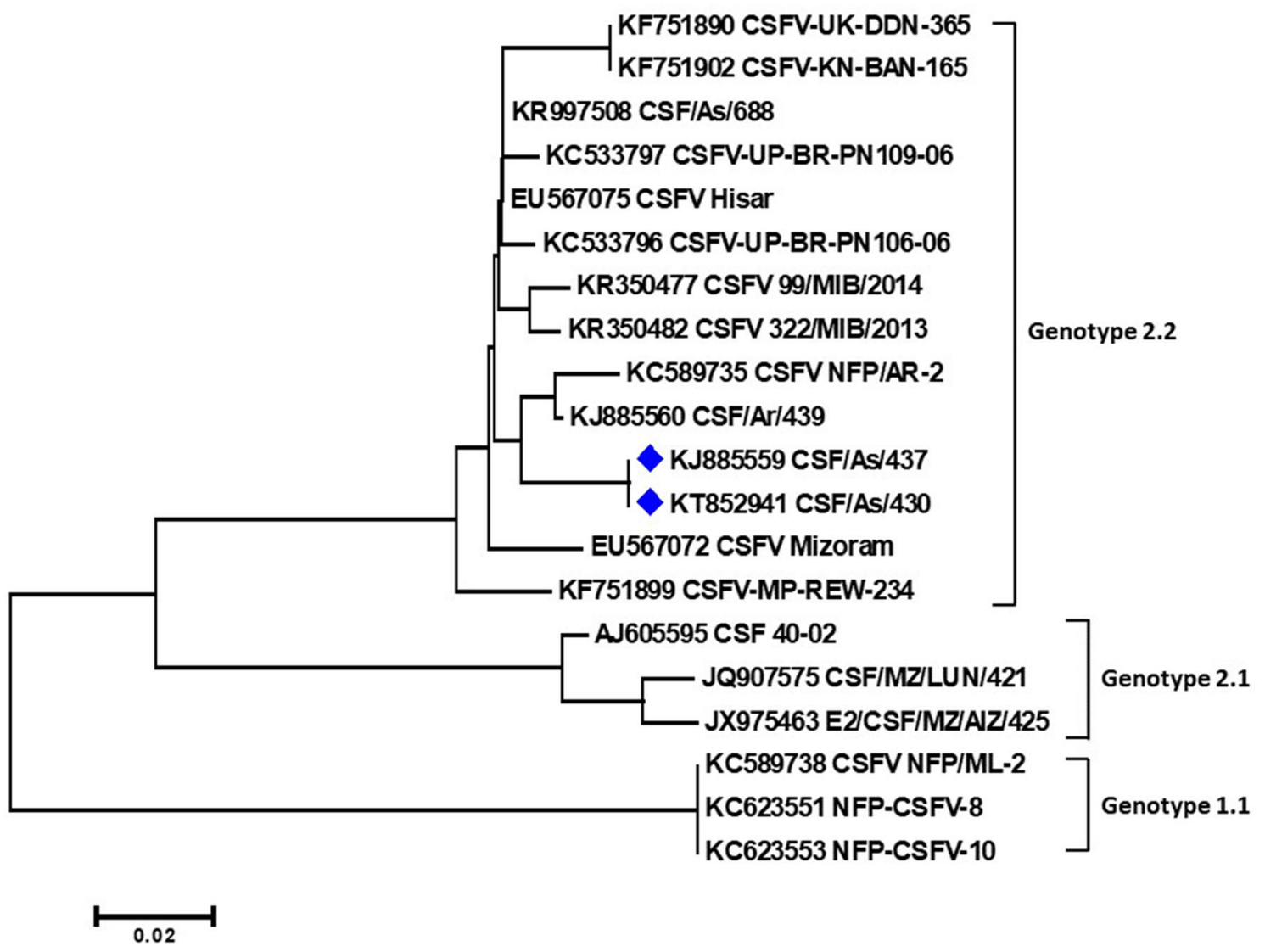

Fig. 6 Phylogenetic tree of nucleotide sequences of E2 gene of CSFV employing neighbour-joining algorithm using MEGA 6 software. The CSFV isolates of the present study, KJ885559 and KT852941 (indicated with blue diamonds) lies within the clade of Genotype 2.2

practice in India. Therefore, laboratory confirmations of CSF antibody titers before and after vaccination should be done in order to assure successful immunization.

The present study took an interesting turn of event when an episode of congenital tremors in piglets was reported in the same premise 4 months later to the initial CSF outbreak. The sows served with CSFV surviving boars resulted in litters that exhibited moderate to severe tremors along with one or two stillborn piglets. As per previous studies, it was found that during an inapparent viremic phase in a pregnant sow, the virus is carried to the fetus and result in embryonic death, malformations, mummification, stillbirth, piglets with tremors or birth of clinically normal persistently infected piglets [28, 39]. Depending upon virulence of CSFV and stage of gestation, the congenitalpersistent form might occur in all or only some fetuses which may or may not die in utero and might survive with retarded development and runting upto 11 months after birth (late onset CSF) until they succumb to death [28]. Even though studies on CSFV associated congenital-persistent form have not been extensively described from infections under natural conditions, previous works on experimental infection to generate transplacental infections resulting into the congenital form $[1,5,12]$ and post-natal persistent form $[7,11,21,30]$ have been documented.

In the present report, the clinical signs observed in piglets died within $24 \mathrm{~h}$ of exhibiting tremors are consistent with the congenital form caused by CSFV. Clinical signs like tremors and hind leg splay in new born piglets, that are indicative of a transplacental CSFV infection in pregnant sows have also been previously discussed in several reports $[1,14]$. The necropsy findings noted in the piglets such as lesions of swollen haemorrhagic lymph nodes and tonsils, petechial haemorrhages in the subcapsular areas of kidneys and multifocal splenic infarction (nearly pathognomonic lesion) were comparable to those as observed in natural acute form of CSF infections. The histopathological findings such as acute glomerular nephritis, depletion of lymphocytes in the splenic corpuscles and lymphoid follicle were in correspondence with the histopathological changes observed in persistent infection of CSFV in piglets [39]. In addition, we were successful in isolating the CSFV strains in PK-15 cells which further provided a phylogenetic evidence indicating the circulation of the same CSFV strain that has been detected in the initial outbreak as well as from the subsequent episode of 


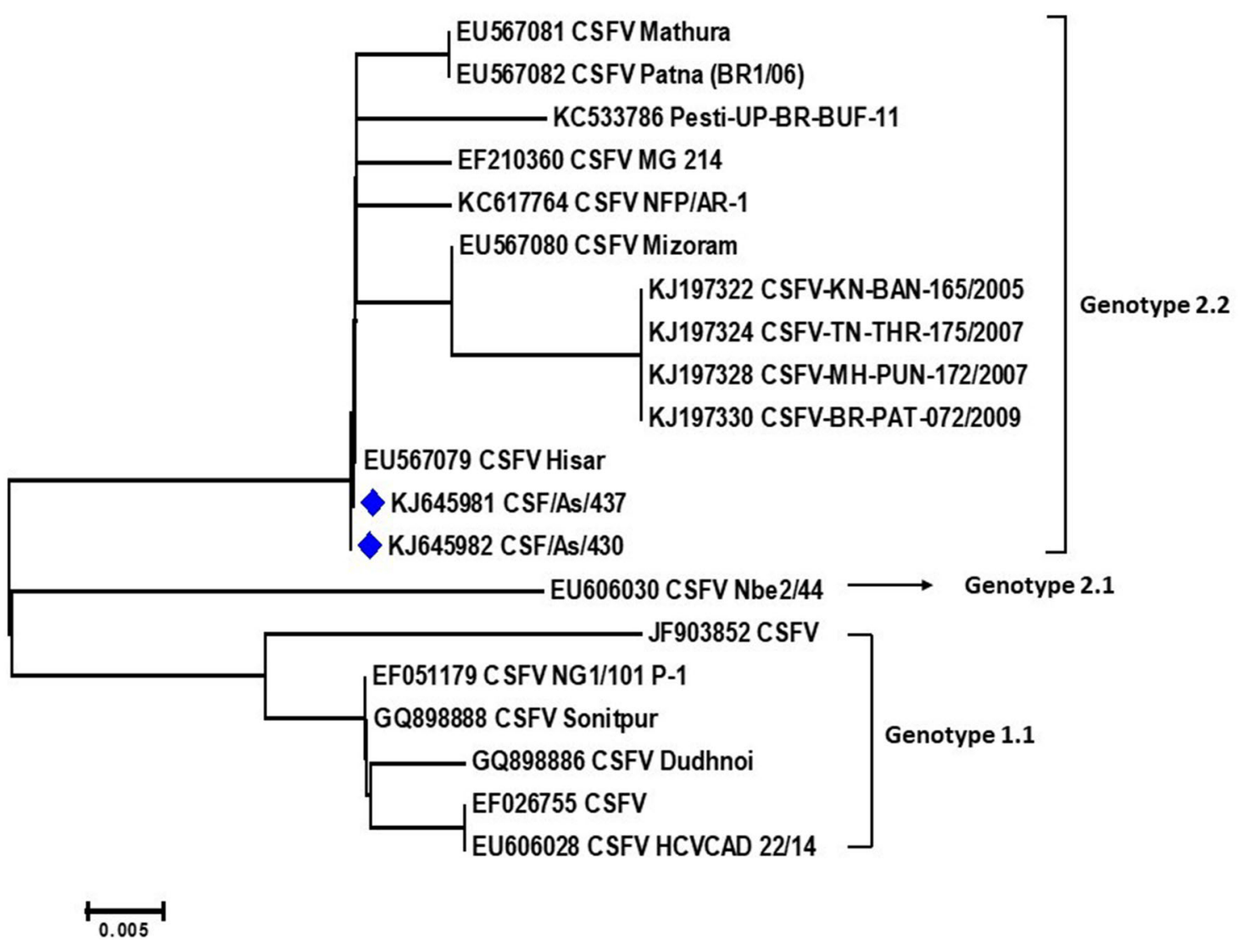

Fig. 7 Phylogenetic tree of nucleotide sequences of 5' NTR of CSFV employing neighbour-joining algorithm using MEGA 6. The CSFV isolates of the present study, KJ645981 and KJ645982 (indicated with blue diamonds) lies within the clade of Genotype 2.2

congenital tremors in piglets. The CSFV isolates that showed nucleotide percent identities of $100 \%$ within themselves were grouped along with Indian isolates of CSFV genotype 2.2, the emerging genotype that is gradually replacing the predominant genotype 1.1 prevalent in India [40].

The pregnant sows, though were previously vaccinated against CSF at 3 months of their age and remained unaffected in the initial outbreak, might have attained the infection under activation of low neutralizing antibody response. As per a recent scientific report, the pathogenesis of CSF congenital persistent form can be related to (i) an efficient trans-placental transmission of CSFV before the onset of antibody response in pregnant sows and (ii) inability of the foetal immune system to recognise the virus and generate an immune response after transplacental infection [5]. The present study, however, could not establish the stage of gestation in which the sows got infected since they remained apparently healthy before service and throughout the gestation period. Moreover, evaluation of CSFV neutralizing antibody titres before mating and during the gestation period were not evaluated assuming the presence of a protective immune response after primary CSF vaccination. Considering the piglets that had been born, we assume that infection with a moderate or highly virulent CSFV have induced the transplacental transmission and resulted in stillbirths and birth of persistently infected piglets. The vertical transmission or pregnant carrier sow syndrome recorded in the present study raised a question of the source of infection in sows that were apparently healthy throughout the gestation period. Transmission of CSFV through semen of boars that have survived the CSFV infection in the initial outbreak and used for natural service within a month of their recovery could be a possible source of the vertical transmission. Previous studies on detection of CSFV in boar semen [15] upto atleast 63 days post infection [8] and recovery of CSFV from foetuses as a result of insemination of gilts with CSFV contaminated semen have been well documented [10]. Therefore, screening of CSFV in boar semen before it is used for natural service or artificial insemination is of significant importance to prevent congenital infections.

In the present report, CSFV induced transplacental transmission presenting the congenital form of CSF was demonstrated. Here, we have provided the evidence of 
CSFV induced congenital form under natural conditions through clinico-pathological and molecular diagnosis. Further, we could establish that the CSFV isolates associated with congenital tremors in new born piglets belonged to the genotype 2.2. Considering the results of the present study, we recommend evaluation of CSFV neutralizing antibody titres after primary vaccination in order to ensure successful vaccination and prevent outbreaks of CSF in domestic pig population. Moreover, vaccines against CSFV indicated for pregnant sows must induce a strong immunity to guarantee viral protection to foetuses against the congenital-persistent form of CSF. To the best of our knowledge, this is the first report of CSFV associated congenital form reported from India under natural conditions. Comprehensive research on congenital form of CSF is few and future studies are required to understand the epidemiology, pathogenicity and immunobiology of CSFV induced congenital-persistent forms.

Acknowledgements The authors wish to thank the Dean and Director of Research, College of Veterinary Sciences, Assam Agricultural University, Guwahati to approve the research.

Funding The work was supported by financial help from Department of Biotechnology, Government of India under the project entitled "Molecular and immunological characterization and phylogenetic analysis of Indian isolates of Classical swine fever virus".

Availability of data The gene sequences used in the study for phylogenetic analysis are available at NCBI database with the mentioned accession numbers provided in the manuscript.

\section{Declarations}

Conflict of interest The authors declare no conflict of interest.

\section{References}

1. Arruda BL, Arruda PH, Magstadt DR, Schwartz KJ, Dohlman T, Schleining JA, Patterson AR, Visek CA, Victoria JG. Identification of a divergent lineage porcine pestivirus in nursing piglets with congenital tremors and reproduction of disease following experimental inoculation. PLoS ONE. 2016;11(2):e0150104.

2. Barman NN, Bora DP, Tiwari AK, Kataria RS, Desai GS, Deka PJ. Classical swine fever in the pygmy hog. Rev Sci Tech. 2012;31:919-30.

3. Belák K, Koenen F, Vanderhallen H, Mittelholzer C, Feliziani F, De Mia GM, Belák S. Comparative studies on the pathogenicity and tissue distribution of three virulence variants of classical swine fever virus, two field isolates and one vaccine strain, with special regard to immunohistochemical investigations. Acta Vet Scand. 2008;50(1):1-13.

4. Blome S, Staubach C, Henke J, Carlson J, Beer M. Classical swine fever-an updated review. Viruses. 2017;9(4):86. https://doi. org/10.3390/v9040086.

5. Bohórquez JA, Muñoz-González S, Pérez-Simó M, Muñoz I, Rosell R, Coronado L, Domingo M, Ganges L. Foetal immune response activation and high replication rate during generation of classical swine fever congenital infection. Pathogens. 2020;9(4):285. https://doi.org/10.3390/pathogens9040285.

6. Bora M, Bora DP, Manu M, Barman NN, Dutta LJ, Kumar PP, Poovathikkal S, Suresh KP, Nimmanapalli R. Assessment of risk factors of African Swine Fever in India: perspectives on future outbreaks and control strategies. Pathogens. 2020;9(12):1044.

7. Cabezon O, Colom-Cadena A, Muñoz-González S, Pérez-Simó M, Bohórquez JA, Rosell R, Marco I, Domingo M, Lavín S, Ganges L. Post-natal persistent infection with classical swine fever virus in wild boar: a strategy for viral maintenance? Transbound Emerg Dis. 2017;64(2):651-5.

8. Choi C, Chae C. Detection of classical swine fever virus in boar semen by reverse transcription-polymerase chain reaction. $\mathrm{J}$ Vet Diagn Invest. 2003;15(1):35-41.

9. Coronado L, Bohórquez JA, Muñoz-González S, Perez LJ, Rosell R, Fonseca O, Delgado L, Perera CL, Frías MT, Ganges L. Investigation of chronic and persistent classical swine fever infections under field conditions and their impact on vaccine efficacy. BMC Vet Res. 2019. https://doi.org/10.1186/s12917019-1982-x.

10. De Smit AJ, Bouma A, Terpstra C, Van Oirschot JT. Transmission of classical swine fever virus by artificial insemination. Vet Microbiol. 1999;67(4):239-49.

11. Depner KR, Müller A, Gruber A, Rodriguez A, Bickhardt K, Liess B. Classical swine fever in wild boar (Sus scrofa)- experimental infections and viral persistence. Dtsch Tierarztl Wochenschr. 1995;102(10):381-4.

12. Dewulf J, Laevens H, Koenen F, Mintiens K, De Kruif A. An experimental infection with classical swine fever virus in pregnant sows: transmission of the virus, course of the disease, antibody response and effect on gestation. J Vet Med Ser B. 2001;48(8):583-91.

13. Direksin K, Chatchawancholtheera A, Pachariyanon S. Serologic profiles of classical swine fever vaccinated backyard pig farms in Khon Kaen Province, Thailand. Indian $J$ Anim Res. 2016;6(4):559-62.

14. Done JT. Congenital nervous diseases of pigs: a review. Lab Anim. 1968;2(2):207-18.

15. Floegel G, Wehrend A, Depner KR, Fritzemeier J, Waberski D, Moennig V. Detection of classical swine fever virus in semen of infected boars. Vet Microbiol. 2000;77(1-2):109-16.

16. Ganges L, Crooke HR, Bohórquez JA, Postel A, Sakoda Y, Becher P, Ruggli N. Classical swine fever virus: the past, present and future. Virus Res. 2020;289:198151.

17. Gonzalez SM. Immunopathogenesis of post-natal persistent infection generated by classical swine fever virus and its implication in the superinfection exclusion phenomenon. $\mathrm{PhD}$ Thesis. Universitat Autonoma de Barcelona. 2017.

18. Greiser-Wilke I, Depner K, Fritzemeier J, Haas L, Moennig V. Application of a computer program for genetic typing of classical swine fever virus isolates from Germany. J Virol Methods. 1998;75(2):141-50.

19. ICTV. International Committee on Taxonomy of Viruses. 10th report. 2021. https://talk.ictvonline.org/ictv-reports/ictv_online_ report/

20. Isoda N, Baba K, Ito S, Ito M, Sakoda Y, Makita K. Dynamics of classical swine fever spread in wild boar in 2018-2019 Japan. Pathogens. 2020;9(2):119. https://doi.org/10.3390/ pathogens9020119.

21. Kaden V, Ziegler U, Lange E, Dedek J. Classical swine fever virus: clinical, virological, serological and hematological findings after infection of domestic pigs and wild boars with the field isolate "Spante" originating from wild boar. Berl Munch Tierarztl Wochenschr. 2000;113(11/12):412-6.

22. Khatoon E, Barman NN, Deka M, Rajbongshi G, Baruah K, Deka N, Bora DP, Kumar S. Molecular characterization of classical 
swine fever virus isolates from India during 2012-14. Acta Trop. 2017;170:184-9.

23. Lowings P, Ibata G, Needham J, Paton D. Classical swine fever virus diversity and evolution. J Gen Virol. 1996;77(6):1311-21.

24. Malik YS, Bhat S, Kumar OR, Yadav AK, Sircar S, Ansari MI, Sarma DK, Rajkhowa TK, Ghosh S, Dhama K. Classical swine fever virus biology, clinicopathology, diagnosis, vaccines and a meta-analysis of prevalence: a review from the Indian Perspective. Pathogens. 2020;9(6):500. https://doi.org/10.3390/ pathogens9060500.

25. Malswamkima D, Rajkhowa TK, Chandra R, Dutta TK. Pathology and molecular diagnosis of classical swine fever in Mizoram. Vet World. 2015;8(1):76.

26. Manu M. Development of alternative potency test for quality control of Classical Swine Fever vaccines. PhD Thesis. Indian Veterinary Research Institute. 2018.

27. Moennig V. Introduction to classical swine fever: virus, disease and control policy. Vet Microbiol. 2000;73(2-3):93-102.

28. Moennig V. The control of classical swine fever in wild boar. Front Microbiol. 2015;6:1211. https://doi.org/10.3389/fmicb. 2015.01211

29. Moennig V, Floegel-Niesmann G, Greiser-Wilke I. Clinical signs and epidemiology of classical swine fever: a review of new knowledge. Vet J. 2003;165(1):11-20.

30. Muñoz-González S, Ruggli N, Rosell R, Pérez LJ, Frías-Leuporeau MT, Fraile L, Montoya M, Cordoba L, Domingo M, Ehrensperger F, Summerfield A. Postnatal persistent infection with classical swine fever virus and its immunological implications. PLoS ONE. 2015;10(5):e0125692.

31. OIE. World Organization for Animal Health. Classical Swine Fever. 2020. https://www.oie.int/fileadmin/Home/eng/Animal_ Health_in_the_World/docs/pdf/Disease_cards/CLASSICAL_ SWINE_FEVER.pdf

32. Patil SS, Hemadri D, Veeresh H, Sreekala K, Gajendragad MR, Prabhudas K. Phylogenetic analysis of NS5B gene of classical swine fever virus isolates indicates plausible Chinese origin of Indian subgroup 2.2 viruses. Virus Genes. 2012;44(1):104-8.

33. Postel A, Austermann-Busch S, Petrov A, Moennig V, Becher P. Epidemiology, diagnosis and control of classical swine fever: recent developments and future challenges. Transbound Emerg Dis. 2018;65:248-61.
34. Qiu HJ, Shen RX, Tong GZ. The lapinized Chinese strain vaccine against classical swine fever virus: a retrospective review spanning half a century. Agric Sci China. 2006;5(1):1-4.

35. Rajkhowa TK, Hauhnar L, Lalrohlua I, Mohanarao GJ. Emergence of 2.1 subgenotype of classical swine fever virus in pig population of India in 2011. Vet Q. 2014;34(4):224-8.

36. Rajkhowa TK, Mohanarao GJ, Gogoi A, Hauhnar L, Isaac L. Porcine reproductive and respiratory syndrome virus (PRRSV) from the first outbreak of India shows close relationship with the highly pathogenic variant of China. Vet Q. 2015;35(4):186-93.

37. Roychoudhury P, Sarma DK, Rajkhowa S, Munir M, Kuchipudi SV. Predominance of genotype 1.1 and emergence of genotype 2.2 classical swine fever viruses in north-eastern region of India. Transbound Emerg Dis. 2014;61:69-77.

38. Sarma DK, Mishra N, Vilcek S, Rajukumar K, Behera SP, Nema RK, Dubey P, Dubey SC. Phylogenetic analysis of recent classical swine fever virus (CSFV) isolates from Assam, India. Comp Immunol Microbiol Infect Dis. 2011;34(1):11-5.

39. Schlafer DH, Foster RA. Female genital system. Jubb Kennedy Palmer's Pathol Domest Anim. 2016;3(2016):358.

40. Shivaraj DB, Patil SS, Rathnamma D, Hemadri D, Isloor S, Geetha S, Manjunathareddy GB, Gajendragad MR, Rahman H. Genetic clustering of recent classical swine fever virus isolates from Karnataka, India revealed the emergence of subtype 2.2 replacing subtype 1.1. VirusDisease. 2015;26(3):170-9.

41. Suradhat S, Damrongwatanapokin S. The influence of maternal immunity on the efficacy of a classical swine fever vaccine against classical swine fever virus, genogroup 2.2, infection. Vet Microbiol. 2003;92(1-2):187-94.

42. Tamura K, Stecher G, Peterson D, Filipski A, Kumar S. MEGA6: molecular evolutionary genetics analysis version 6.0. Mol Biol Evol. 2013;30(12):2725-9.

43. Trautwein G. Pathology and pathogenesis of the disease. In: Classical swine fever and related viral infections. Boston: Springer; 1988. p. 27-54.

44. Vannier P, Plateau E, Tillon JP. Congenital tremor in pigs farrowed from sows given hog cholera virus during pregnancy. Am J Vet Res. 1981;42(1):135-7.

Publisher's Note Springer Nature remains neutral with regard to jurisdictional claims in published maps and institutional affiliations. 